\title{
Martí y Martínez Estrada : Historia de una Simbiosis Espiritual
}

En 1974, el crítico irlandés Denis. Donoghue publicó un libro titulado Thieves of Fire, ${ }^{1}$ examen breve e ingenioso de un estado mental -- imaginativo -- que denominó prometeico, estado que está reflejado en las obras de Milton, Blake, Melville y D.H. Lawrence. El alegato del Profesor Donoghue consiste en apuntar un proceso imaginativo que describe la dádiva del entendimien co humano -- metáfora del "fuego" robado a Zeus por Prometeo -como el modelo ejemplar, paradigmático, del quebrantamiento de todos los preceptos abstractos -- por ende, irreales -- en nombre de la humanidad; o sea, una rebelión contra todo código, aún contra los divinos. Escritores con ése tipo de mentalidad, alega Donoghue, son aquellos en quienes la obstinación, la porfía y aun la herejía son la razón y guía de su existencia, acompañadas estas cualidades con una confianza y fe en sí mismos tan poderosa que ninguna otra pudiera siquiera comparárseles en intensidad o en vehemencia. Este sentir prometeico, dice Donoghue, proporciona al agente un sentimiento de exaltación ante lo riesgoso, así como la determinación de sostener tal experiencia por medio de un acto siempre conciente y perenne de la voluntad. Con ese sentido preponderante de su fuerza, tales mentalidades imaginativas intentan encontrar en el medio ambiente y en el hombre mismo los medios para sus fines, no cediendo jamás -- ni siquiera al final de su vida -- al dominio de lo inconsciente o de lo oculto. ¿Cabe Martínez Estrada en este panteón? Creo que sí.

Ahora bien, si comparáramos lo dicho sobre este tipo de actitud imaginativa con la misma mentalidad en Ezequiel Martínez Estrada, encontraríamos que estudiosos de su obra literaria no han encontrado el mismo nivel dogmático-imaginativo que el Profesor Donoghue cree ver en la imaginación candente de escritores como Melville y. D.H. Lawrence. En un libro reciente, el Profesor Peter Earle resuelve cualquier problema sobre este particular -- si bien de manera un poco simplista -- al declarar a Ezequiel Martínez Estrada miembro de " una distinguida asociación de intelectuales desajustados que incluye a Montaigne, Schopenhauer, Thoreau, Nietzsche y Kafka.', 2 Esta visión elemental del

\footnotetext{
${ }_{1}^{1}$ Denis Donoghue, Thieves of Fire (New York: Oxford University Press, 1974) pp. 15-30.

2 Yeter Earle, Prophet in the Wilderness (Austin: University of Texas Press, 1971) xii.
} 
perfil imaginativo de EME no nos indica en modo alguno la verdadera naturaleza de las coordenadas -- constantes -- de la psiquis del ensayista argentino ni tampoco nos abre perspectiva alguna hacia la clase de interacción imaginativa entre el mundo -- circunstancia del escritor -- y éste; interacción que bien puede considerarse consistente y sólida a través de toda su obra, desde sus primeros artículos, publicados en octubre y diciembre de 1917 en la revista Nosotros, pasando por Radiografia de la pampa, La cabeza de Goliat, Sarmiento, Muerte y transfiguración de Martin Fierro, hasta su etapa final -- su examen de la vida y la ideología de Jose Martí, obra de tres tomos.

Parte de mi propósito en este estudio será tratar de determinar algunos de los radios vectores del parámetro imaginativo de Ezequiel Martínez Estrada, para llegar a los conductores que desde su alma lo empujaban hacia un rumbo constante, fijo, a través de toda su vida, aunque pudiera ser que algún observador poco atento de la obra de este autor notara tan sólo un pantano caótico, con base en un ciego y mal considerado anarquismo a gran escala, veteado de paranoia y de complejos de martirologio.

Ante todo, debemos dejar a un lado el epíteto de "negativista" con el cual se asocia frecuentemente a Martínez Estrada, así como la palabra "inutilidad' ' con la cual se asocia la aparente ataraxia del espíritu. "Martinez Estrada fue, espiritualmente, un anarquista," nos informa el Professor Earle -- "que -- como tantos otros anarquistas -- se consumió en pensamientos reyolucionarios y que redujo su participación en la lucha a la palabra escrita y oral." 3 En esta misma línea, el entonces joven peronista Juan José Sebreli tituló su filípica contra nuestro autor Ezequiel Martinez Estrada -- una rebelion inutill. ${ }^{4}$ Creo que la línea seguida por Sebreli es, para los propósitos que nos ocupan, un callejón sin salida, y que la misma sólo puede conducir a la repetición de lugares comunes peronistas sobre el valor trascendente de un activismo fanático, que si está bien para "actuar" en un café, no tiene por qué ser considerado cuando se evalúa seriamente la labor de Don Ezequiel.

Un modo de acercarse a Martínez Estrada sería edificar un panteón con sus escritores predilectos -- aquellos autores hacia quienes se sentía atraído poderosamente. Como ha sugerido el Profesor Earle, es cierto que estos escritores tienen todos algo del hombre insurrecto, pero es igualmente cierto que todos y cada uno de ellos poseen la facultad de oír, de escuchar atentamente la voz de su conciencia, o como lo expresara magistralmente Henry D. Thoreau, "marchan al compás de un tamborilero que solamente ellos pueden oir." Al mencionar a Thoreau tenemos que detenernos un momento para convertirlo un ejemplo del tipo de imaginación que tratamos de concretar. La famosa cita de Thoreau nos trae a la mente el encarcelamiento de su autor, asi como el hecho de que su teoria sobre Desobediencia Civil fue motivada por el impuesto adicional sobre ingresos implantado por el gobierno de los EE. UU. para poder costear -- y mantener -- su guerra con México. En un artículo publicado en el primer número de la Revista de la Casa de las A méricas (1960) y luego recogido en la colección de artículos titulada En torno a Kafka, Martínez Estrada muestra una honda simpatía por el método de Thoreau:

\footnotetext{
3 Ibid., p. 19.

${ }^{4}$ Juan José Sebreli, Martinez Estrada: Una rebelión inútil (Buenos Aires: Editorial Jorge Alvarez, 1967). $2^{\text {a ed. }}$ (La $1^{\text {a }}$ edición es de 1960).
} 
Empero, preso por no pagar el impuesto que se le exigía para robarle tierra a. México y matarle su gente, concibió (Thoreau) la idea de que contra el fusil sólo es eficiente la voluntad que dice " no quiero." Decir que no, resistir y dar la vida si es preciso, es la única fuerza que hoy tienen los pueblos inermes para defenderse y liberarse de sus carceleros atraillados... ${ }^{5}$

Ese "no", esa negación a todo lo que no sea humano, a todo lo estratificado, a todo lo estructurado, codificado y abstracto, es, para Thoreau y para EME, el único método corrector con el cual la superestructura del estado puede ser moldeada para satisfacer las necesidades del ser humano. Y este anteponer la necesidad de libertad humana a las necesidades del estado, arrastra a EME -- como antes arrastrara a Thoreau -- al campo de la revolución y la utopia hechos realidad. Es a partir de este punto, como utopista, que examinaré la obra de Martínez Estrada. Los aspectos negativos, tan arbitrariamente discutidos por sus críticos, son simplemente una faceta inicial de renuncia psíquica, pasos preliminares encaminados hacia un programa y una estructura y uná orden, que le ofrecerá al mismo tiempo la emancipación personal y política. Esto, a su vez, significa que a Ezequiel Martínez Estrada no se le puede considerar de otra forma que no sea como representante de todo aquello que nos es humanamente sagrado--y es posible que en un tiempo no muy lejano EME sea considerado como el sumo sacerdote de un humanismo politizado, prototipo de un panteísmo ilimitado, libre, sin trabas, un verdadero comunalista espiritual. Al llegar aquí surge nuevamente la figura de D.H. Lawrence. Tanto éste como EME añoraban no el mundo presente sino el de los comienzos--les exasperaba no haber participado en los comienzos de la experiencia humana sobre el. planeta. Ambos sentían afinidad con el mundo animal y vegetativo: flor ninguna jamás les había insultado o había sido obstáculo en el camino de su libre albeldrío. ${ }^{6}$ La ilusión de libertad en un medio rústico--ese beatus ille--que EME compartía con su fraternal amigo Horacio Quiroga se convertirá en una de las ideas constantes, fundamentales, de su vida y como tal debe tenerse en cuenta cuando analizamos el itinerario que siguieron las ideas de nuestro ensayista. Como veremos, esta visión paradisíaca guiará la interpretación que nos dará EME del regreso de Martí a Cuba, luego de quince años de exilio forzoso en las EE.UU. Así, podemos decir que Martínez Estrada y Martí se sentían como hijos de la madre naturaleza, parte de esos seres que, como Thoreau, "Luchan casi siempre con riesgo de su bienestar y de su vida, para desbrozar el mundo primario en que vive satisfecho el ciudadano de las grandes urbes cosmopolitas. Con sólo la preceptiva de los antiquísimos filósofos de los bosques, sin sociología política, Thoreau no sólo pensó paradojas de esta clase sino que las puso en práctica viviendo conforme a ellas...Construyó su casa, vivió de lo que él producía, y, sin metáforas, al partir dejó a su país un poquito más limpio, ordenado y dichoso de como lo encontró." 7 Lo mismo se puede hacer con ottos de sus escritores favoritos; así, a su manera, cada uno de ellos tiene algo que decirnos sobre EME, cada uno de ellos viene a ser como una parte, como una pieza en el rompecabezas de la visión de sus

\footnotetext{
5 "La mansa idea revolucionaria de Thoreau," En tomo a Kafka (Barcelona: Seix Barral, 1967)p. 100.

- Ver Donoghue, op. cit., p. 29.

7 “'Henry David Thoreau,' 'En tomo a Kafka, p. 90.
} 
héroes--Balzac, Nietzsche, Quiroga, Schopenhauer, Simone Weil, para citar algunos--y de su idolatría. Pero debemos mencionar otra figura, que aparece casi al final de su vida--un semidiós, un ente casi divino--José Martí--prototipo del héroe que persevera en su empresa a pesar de barreras infranqueables, hasta lograr el triunfo de su causa. Es debido a esa caracteristica, a ese tesón, que creo que Martí revolucionario (el primer volumen de la trilogía) sea el legado más importante que nos ha dejado EME, más importante aún que Radiografia de la pampa. Esta última obra ha sido considerada, sin embargo, como su obra típica, únicamente desde el punto de vista de su análisis critico sobre los males que aquejan a la Argentina; pero es un análisis falto de alegatos políticos y económicos, obra que es más bien su visión de la pampa y la ciudad de Buenos Aires, "su" cabeza de Goliat.

Si consideramos el campo de su imaginación como sobreextendiéndose por encima del campo político y literario, veremos como EME no fue el paradigma de la víctima resignada con su destino y con su suerte que alguna crítica negativa nos presenta. El único sentido de predestinación o aceptación de un determinismo psíquico en EME reside en el sometimiento voluntario a su voz interior, su obediencia a los dictados de ésta y nunca a los placeres o atracciones mundanas. Esta voluntad de acero que encontró en la vida de Nietzsche, por ejemplo, también la halló en la vida de Martí, que poco a poco él inviste con los atributos de una grandeza mítica, así como de un sentido ucrónico y mesiánico que EME asocia con una edad homérica que, si bien ya perdida, se podría recuperar nuevamente a través de la vida del prócer.

Nos estamos refiriendo, como lo habíamos hecho al principio de nuestro estudio, a un cierto mecanismo imaginativo que es y será siempre constante en Martínez Estrada, o sea, la voluntad de un "hereje" en función de un Ezequiel de antaño que consideraba el mundo como lugar injusto y moralmente envilecido. Si esta visión del mundo es prometeica, es también sumamente, profundamente moral ya que el portador del fuego se percata de que si no encuentra quien reciba su dádiva, ésta se perderá, y su raison d'être en el mundo dejará de tener sentido.

No mentirse a sí mismo, no tener miedo, no detenerse a mitad del camino sino llegar hasta las últimas consecuencias, o hasta las últimas posibilidades de llegar; ser un vikingo, ésa es su misión ${ }^{8}$ (la de Nietzsche)...En fin, su destrucción de todo fundamento racional del cristianismo le restituye su primigenia fuerza... ${ }^{9}$

Otro aspecto de la personalidad de EME pudiera ser una búsqueda| de su propio historicismo, búsqueda para lograr una meta final con la cual dar cima a su carrera de escritor y de crítico social, desmintiendo así a aquéllos que tranquilamente le acusaban de negativo, autor de inútiles jeremiadas contra todo y contra todos. Creo que éste su concepto de historicidad personal está aliado a su concepción -- de tipo patológico -- de lo heroico. Esto es en sí importante y hay que aclararlo. En la Radiografta de la pampa encontramos el siguiente pasaje:

Es preciso que exista un estado de historicidad, una forma histórica completa

8 “"Nietzsche, filósofo dionisiaco," en Heraldos de la verdad (Buenos Aires: Editorial Nova, 1957)p. 189.
${ }^{9} \mathrm{Ibid.,} \mathrm{p.} 176$. 
para que el hecho tenga un sentido vivo y no de complemento circunstancial. En tal medio histórico cuanto acontece es irremisiblemente historia...cualquiera que sea el valor intrínseco de nuestras batallas, quedan desgajadas del árbol genealógico de la historia. ${ }^{10}$

Un modo de interpretar la residencia de EME en Cuba, su participación en el destino de dicho país y, finalmente, la preparación de los tres volúmenes sobre José Martí, sería considerar todo esto como su última tentativa hacia el logro de la historicidad del individuo, i.e., su propia historicidad dentro de un medio que él consideró como "una forma histórica completa." Dicho de otra manera, sugiero la interpretación de que, consciente $o$ inconscientemente, EME intuyó su residencia en Cuba (así como la simbiosis de su espíritu con el de Martí) como la confirmación definitiva del papel con el que siempre había soñado pero que había tenido que "'vivir" en la vida de otros (Montaigne, Schopenhauer, Nietzsche, Unamuno, Kafka, et al) y que jamás pudo realizar en la Argentina. De ahí que veamos su fase cubana como un esfuerzo masivo por parte de su voluntad para llegar a satisfacer sus deseos de militancia política activa y reencarnar de la mejor manera posible -a través de la figura mítica de Martí -- la militancia, el activismo y el fervor que tanto admiró en aquellos héroes del pasado que fueron sus predilectos.

A hora bien, ¿cuáles fueron los elementos que en EME y en la circunstancia política de la Argentina y Cuba que le condujeron hacia esa especie de apocalípsis ideológica que ronverge sobre él durante su período cubano? Primero que nada, debemos recordar que en 1955, con la caída de Perón, EME se recuperó de la neurodermitis melanica -- enfermedad de carácter psicosomático -- que había convertido su piel en una especie de cuero oscuro, al que se refería como "mi piel de elefante." Al desaparecer Perón de la vida política, desaparece también el mal que aquejaba a Martínéz Estrada y que él había autodiagnosticado como "peronitis." En 1957 fueron publicadas las siguientes obras: El hermano Quiroga, Heraldos de la verdad (que contiene estudios sobre Montaigne, Nietzsche y Balzac), así como se reeditaron la Radiografia de la pampa y La cabeza de Goliat; además, la Sociedad Argentina de Escritores organizó una ceremonia conmemorativa del vigésimoquinto aniversario de la publicación de Radiografia... A Aparentemente, en vista de todo lo anterior, parecería como que EME, al fin, comenzaba a recibir la fama que su país le había negado durante veinte años. Sin embargo, en 1958, Juan José Sebreli terminó el manuscrito de una obra que vino a ser el ataque más frontal y vitriólico contra EME y los trabajos cumbres de éste publicados hasta aquel entonces. Me refiero a Martinez Estrada, una rebelion inutil. Existe un pasaje en esta obra -- tendenciosa y maliciosa como un folletín -- que toca el punto de la inercia, del inactivismo político en Martínez Estrada y que sospecho tiene que haber afectado profundamente a Don Ezequiel:

Como los antiguos epicúreos, Martínez Estrada reniega de toda forma de acción: el pensador debe aislarse del mundo, despreocuparse de la cosa pública, encerrarse en sí mismo para consagrar toda su vida a la búsqueda de la verdad...Pero, si pensamos...que la verdad es esencialmente temporal, que se va revelando a medida que se crea en el curso de la historia, entonces el pensador debe 
huir de la soledad y del aislamiento absoluto, para confundirse con el mundo...Pero Martínez Estrada no quiere que su crítica de la sociedad se realice nunca. Se complace en su indignación frente a una sociedad injusta y teme de que ésta sea verdaderamente cambiada, porque no tendría entonces motivo para indignarse, es decir, se quedaría sin su razón de ser, sin su papel de denunciante profesional...Como el neurótico se aferra a su enfermedad, EME se aferra a su escepticismo y no quiere la construcción de un mundo mejor, ya que tendría que aceptarlo y resignarse a ser como todos... ${ }^{11}$

Aunque es difícil saber a ciencia cierta cuando haya visto EME el manuscrito de ese libro--fue publicado por fin en 1960--creo vislumbrar un cambio en su manera de pensar hacia fines de 1958. Por ejemplo, en su "Homilía a los estudiantes," un discurso dado en la Universidad Nacional del Sur, en Bahía Blanca, el 20 de diciembre de 1958, EME amonesta a "los educadores...que corrompen y envilecen. Desoíd, pues, los malos ejemplos con que se deseduca al pueblo y se le inculcan enseñanzas perniciosas; y no olvidéis que, según testimonio fidedignos, Satanás habla desde los palacios de los poderosos y el Señor desde las cabañas de los pescadores...Los educadores más efectivos son los que enseñan con el ejemplo." 12

Al concluir este discurso, EME declara que

Si yo tuviera que vivir dialogando con Ford, Taylor y Stajanov en vez que con Montaigne, Balzac y Nietzsche, me sentiria muy desdichado. Me sentiría esclavizado, enyugado en una noria de complicado mecanismo.

¿Qué para llegar por fin a la libertad de Montaigne, Thoreau y Simone Weil es preciso atravesar el infierno de las fábricas y de las cárceles? De acuerdo: pero no con la resignación de quedarnos en ellas sino para atravesarlas, como Dante, hacia el paraíso: una estada infernal hacia la libertad y la justicia verdaderas. ${ }^{13}$

Ese matiz utópico se tornará en el sello característico de los escritos de Martínez Estrada durante su período cubano. Poco más o menos un año después, comienza Don Ezequiel sus importantes colaboraciones en las revistas literarias de la Revolución. Entre esas colaboraciones podemos señalar dos artículos clave: "Prolegómenos a una revaluación de las letras argentinas," que apareció por primera vez en Nueva Revista Cubana, $1^{\circ}$ número, 1960, y "La mansa idea revolucionaria de Thoreau," publicado originalmente en $L a$ Revista de la Casa de las Américas, $1^{\circ}$ número, junio-julio de 1960. Tales trabajos conllevan, de por sí, aspectos significativos, sobre todo cuando en el artículo de Nueva Revista Cubana señala EME que

El escritor ha sido, en los EE.UU., desde los albores de la nacionalidad, agente

\footnotetext{
${ }^{11}$ Sebreli, op. cit., pp. 99-102.

12 "Homilía a los estudiantes," en Para una revisión de las letras argentinas (Buenos Aires: Losada, 1967) p. 169.

${ }^{13}$ Op. cit., p. 177 .
} 
de independencia individual y de progreso, francotirador o anarquista intelectual, como también se lo ha llamado. ¿Hemos buscado en ellos a nuestros modelos, como los hemos buscado en los teóricos de las libertades políticas y de la organización de Estado? Siempre hemos preferido imitar làs formas, lo que podría designar como el aspecto retórico y formulario de las ideas. Cuando resolvimos emanciparnos de España buscando nuestra propia expresión caímos en la tutela de Francia y nos enrolamos en otras tropas. ${ }^{14}$

De lo anterior concluímos que está claro que EME (no tan sólo en el artículo citado sino también en el otro) reconoce que la emancipación política no tiene casi nada que ver con la emancipación espiritual y que el abandono masivo de la ideología occidental sobre la teoría del "progreso" y sobre el "gradualismo político" es el sine qua non para encontrar lo que él llama la expresión nacional. En este punto, debemos tener presente Les Damnés de la terre, de Frantz Fanon, y las ideas que alli se encuentran, sobre todo en el capítulo que toca sobre el nacionalismo cultural. Esta obra, a la que se refirió Martínez Estrada en el prólogo de su última obra, publicada por el Fondo de Cultura Económica-- Antologia--, bajo el epígrafe "Prólogo Inútil,", 15 confirmó en forma virulenta muchas de las tendencias filosóficas del pensamiento de Don Ezequiel durante su participación en los primeros años de la Revolución Cubana. Claramente, dicha participación indicaria un gran interés por parte de Martínez Estrada no tan sólo en las actividades de la Casa de las Américas, sino también en la suerte y el destino de la Revolución, por aquel entonces en su fase inicial más crítica. Lo cierto es que EME habla sido invitado por el F.C.E. (en Setiembre de 1959), a participar en las ceremonias conmemorativas del vigésimo quinto año de la fundación del Fondo. Al mismo tiempo, la Universidad Nacional Autónoma de México le había extendido otra invitación, de tipo académico, para que ocupara por espacio de un año la cátedra de profesor visitante en la Escuela de Ciencias Políticas. Pero justamente también por la misma época, comienza su correspondencia con Roberto Fernández Retamar. La primera carta está fechada durante el otoño de ese año, el 19 de setiembre de 1959, para ser exactos. En ella, habla del destino de Cuba :

Como ni mi cuerpo ni salud tienen nada que ver conmigo, quiero servir a mis hermanos cubanos en cuanto pueda y sepa, y sin ningún interés...Ansío estar con usted en estos momentos decisivos en que Cuba puede decidir la suerte de la América Latina, y recibir de usted la firmeza y seguridad de ideas que todavía no tengo claras. Iré, pues, a recibir mucho más que a dar. No se haga ilusiones sobre el provecho que puedan ustedes obtener de mi visita: piense más bien en que es mucho lo que tengo que aprender de ustedes, y con ese ánimo voy. ${ }^{16}$

Martínez Estrada llegó a Cuba el 16 de febrero de 1960 para quedarse unos meses. Durante

14 Artículo luego recogido en Para una revisión. . . , pp. 11-24.

15 (México: FCE, 1964) También publicado por César Fernández Moreno en su La realidad y los papeles (Buenos Aires: Aguilar, 1967) págs. 581-587.

16 Samuel Feijóo, "Para un epistolario cubano de Ezequiel Martínez Estrada" Islas, (julio-septiembre 1965,) Vol VII, núm 2, pp. $72-73$. 
esta estancia dió dos conferencias sobre Martí y comenzó una investigación en gran escala no sólo sobre los escritos y la vida del prócer, sino también sobre los posibles aspectos mítico-alegóricos de su vida, una vida entregada total y plenamente a la consecución de la libertad de Cuba y a un ideal de Revolución. La mejor prueba de lo completamente imbuído que estuvo Martínez Estrada en esta tarea la tenemos no tanto en los tres volúmenes sobre Martí, sino más bien en la antología que intituló Mi experiencia cubana. Creo que el ensayo clave de esta obra es el que lleva por título "El mausoleo de Marti," 17 sobre todo porque en esas páginas está grabada hasta el detalle más insignificante, la idea de su misión en Cuba: ante todo, edificar un monumento de tipo épico a Martí y al ejemplo revolucionario dado por éste, arrancar a Mart' del nivel de "frivolidades suntuosas de provinciano lucimiento, $" 18$ o, todavía mejor, salvar a Marti de los especialistas en José Martí, que producen, en la opinión de Martínez Estrada, tan sólo "bagatelas propias de profesor de liceo." 19 Además--y sobre todo--quería salvarlo de los estetas martianos. Entonces, su Martí será todo menos un "Martí de mármol" -- será un ente vivo, palpitante, completamente humano. El médium que efectuará la resurrección de Martí en nuestra época será un avatar de Martí: Ezequiel Martínez Estrada, imitador obsesionado de Martí; Ezequiel Martínez Estrada, ente envuelto, al fin, en una relación de tipo simbiótico para con los principios heroicos de la vida que Martí ejemplifica tan evidentemente; Ezequiel Martínez Estrada, nuevo acólito de la religión de pureza moral y de acción revolucionaria; Ezequiel Martínez Estrada, en adelante no "él" mismo sino "Ezequi--El Martí--nez Estrada." De esa manera firmó su nombre en la extraordinaria carta del 17 de agosto de 1962 que dirigió a Samuel Feijóo. ${ }^{20}$ Volviendo ahora al ensayo-meditación escrito por Don Ezequiel ante la tumba de Martí, veremos allí dos o tres ideas importantes: Martínez Estrada menciona cómo su "habilidad natural al culto de los héroes," se despierta nuevamente en él, inquietándolo, al contemplar el mausoleo de Martí, pero ese sentimiento surge precisamente porque el mármol impertérrito no posee esencia humana alguna:

El sentimiento o el instinto de la grandeza humana, y lo diré, el respeto y el culto a los héroes, los santos, los sabios, los artistas y los filántropos llegan en mí a la idolatría, pero no al fetichismo, a la iconolatría de los imagineros, de los custodios de los trofeos, las panoplias y otras reliquias de armería... ${ }^{21}$

En la cita anterior, el eje principal parece ser: ¿Cómo reconciliar el impulso heroico con aquel que lleva hacia la falsificación, la distorsión de un heroe vivo para convertirlo en un ídolo muerto, inhumano, en un mito vacuo? En estas páginas, EME ve claramente la labor a realizar:

17 Mi experiencia cubana, (Montevideo: ' El siglo ilustrado, 1965) 'El mausoleo de Martf' se encuentra en las págs. 207-219.

${ }^{18}$ Marti Revolucionario (La Habana: Casa de las Américas, 1967), p. 527.

19 Op. cit., p. 486.

${ }^{20}$ Islas, op. cit., p. 81.

21 "El mausoleo de Marti," p. 210. 
A Martí se le ha tratado en tamaño gigantesco, no en magnitud gigantesca, ahora lo veo, porque no se le ha querido de corazón con humildad filial... ¿ No se lo rescatará, no se lo repatriará, no se lo traerá del destierro de mármol y bronce, no se lo hospedará y se le lavarán los pies de su peregrinación en el hogar de todos, en la república de trabajo, honra, amor y paz?...Devolvámoslo a toda Cuba en vez de encerrarlo en una cripta...que no tenga una efigie de mármol o de bronce que se le parezca...donde un grupo de cubanos se reúne para adelantar la liberación de Cuba. está él... ${ }^{22}$

Esta labor de evangelista--gigantesca desde el punto de vista de sus ambiciones como biografo martiano y al mismo tiempo un ejercicio de autohumillación, devoción total y entrega absoluta--encarna la tarea que EME se impone como meta final para con la grandeza y dignidad humana, y ésta a su vez representada por la figura de Marti, -una figura que aglutina y cambia los destinos de una nación. Este trabajo será también, a fin de cuentas, tanto una labor de autodescubrimiento del autor como de develamiento del papel de Martí como hombre y como pensador político. "Yo creo un deber martiano sacarlo de debajo de los escombros y los confetti que le han echado encima los señores profesores de Retórica para que le veamos a la luz del sol."

Tengamos presente mientras tanto, que el género "biografia" siempre gustó a Martínez Estrada. Prueba de ello son sus volúmenes sobre Sarmiento, Nietzsche, William Henry Hudson, así como los estudios brillantes, , más breves, sobre Pedro Henriquez Ureña, Helen Keller, Simone Weil y otros donde la visión psicológica es penetrante. Tendríamos ahora que preguntarnos si existe alguna explicación para este gusto en Don Ezequiel. Después de todo, los personajes elegidos por él no caen en la categoría de biografiados "populares'" como, por ejemplo, aquéllos a los que se dedica André Maurois. Las biografías de Martínez Estrada son, frecuentemente, transposiciones psíquicas de su yo interno hacia otros tiempos y sujetos. A esto hay que añadir que sus biografiadosson entes que se desbordan al plano simbólico y a niveles historicistas: para EME no hay vida que se desarrolle en un vacio, cada vida es una alegoría del tiempo que le cupo vivir. De acuerdo con esta visión, no hay accidentes, sucesos en la historia: aún en el pasado, todo y todos tienen un papel que realizar, papel de importancia orgánica en el devenir de la historia. Así, la tarea del biógrafo será dar la mayor historicidad posible a la figura de la que se ocupa. Este acercamiento --recuérdese a Spengler; mejor aún, a Herder--podemos verlo en una cita de EME que encontramos en su Sarmiento:

La inclinación de Sarmiento a escribir biografías, por lo tanto, se concierta en él con una modalidad conminatoria de la realidad, y hasta en eso refleja su identificación con los problemas y con la vida del pais...todas sus biografías, argentinas o americanas, condensan en contenido mental formas fundamentales de su concepción de la historia...La biografía así considerada asume--cualquiera sea su extensión--el valor de un símbolo, o para decirlo con más estrictez, de una metáfora, 
como medio de hacernos más comprensibles lo abstracto o las relaciones abstractas entre las cosas. ${ }^{23}$

Lo anterior es importante no sólo porque clarifica el impulso historicista en EME sino porque es también una clave de la clase de biografía total que tenía como ideal; los hechos, desde luego, pero junto a ellos cada impulso, idea y pasión que los produjo. EME comenzó sus trabajos sobre Martí luego de haber sido invitado en firme por la Casa de las Américas, en octubre de 1960. Residirá en Cuba por espacio de dos años poco más o menos, trabajando en su libro y dictando seminarios sobre teoría política. No se marchará hasta noviembre de 1962, deteniéndose brevemente en México y siguiendo hacia Bahía Blanca, Argentina. Según indican sus cartas a Samuel Feijóo, Martínez Estrada deseaba ver su obra final en prensa antes de morirse, pero esto no le sería concedido, ya que moriría el 3 de noviembre de 1964, en su hogar en Bahía Blanca. Por una de sus últimas cartas a Feijóo, sabemos que la trilogía estaba casi completa al morir su autor: el primer volumen, titulado Marti revolucionario, lleva el subtítulo de "La personalidad, el hombre." La segunda parte, según creo aún no publicada (el manuscrito todavía está en Bahía Blanca) se titula La doctrina, el apóstol. El tercer volumen, un examen crítico del ethos revolucionario e ideológico de Martí, tiene por nombre Martt: el béroe y su acción revolucionaria. El primer volumen ha sido publicado por la Casa de las Américas; el tercero, por Siglo XXI, de México. Se espera que el comité profesorial de la Universidad del Sur dará pronto a la imprenta el segundo volumen.

En mi opinión, el interés principal de la trilogía reside en el primer volumen, ya que es en éste y solamente en éste donde podemos observar atentamente la personalidad deEME en la etapa final de su desarrollo espiritual. En este libro, Martínez Estrada edifica su visión prometeica de Martí; allí lo eleva de un ente físico, real y concreto, hasta convertirlo en una fuerza inefable y mística, un semidiós sujeto a ritos de iniciación y a pruebas de fuego hasta llevarlo finalmente a la consecución de una muerte apoteósica. Todo esto, de carácter claramente mítico, está a la vez documentado por las condiciones de vida miserable en que vivió Martí junto a su noble idealismo; cada hecho apuntado por el biógrafo está visto no solamente desde el hecho en sí, sino como punto de referencia sostenedor de una estructura fatalmente determinista, con un sentido casi suicida de predestinación y muerte.

El Martí visto y sentido por EME reúne los hechos cotidianos inseparados de una alegoría ucrónica, presentado todo en una estructura biográfica única. Esta biografía se convierte así en un esfuerzo que, paradójicamente, eleva la figura de Martí a cimas nuevas de significación y sentido, pero que, al mismo tiempo nós presenta a un Martí incrustado en su sórdida, degradante y opresiva circunstancia económica, sobre todo durante sus años de exilio en Nueva York. El hilo conductor que une los hechos con la alegoría es, claramente, la penetrante visión de EME con respecto al sentimiento de misión prometeica de Martí, misión de una idea política por la cual supo abandonarlo todo-inclusive esposa e hijo-con tal de llevarla a su consecución. A pesar de que su visión de idólatra martiano presenta a Martí muy favorablemente, no podemos dejar de ser impresionados por lo que dicha obsesión lleva implícito: el precio psíquico y humano pagado por Martí durante toda 
su vida con tal de realizar, lograr, las metas revolucionarias de su misión. Así, lo que es biografia en esta obra desaparece - o cuando más, pasa a un segundo plano,y se convierte en historia de Cuba; la personalidad martiana pasa a ser el principio vivo, activo, de revolución y rebelión hacia el logro de la justicia social. La subliminación del principio ególatra es una característica esencial que se reitera constantemente a través de las 617 páginas del primer tomo. EME observa en Martí un sentido de disociación para con su yo, y esto le parece parte integral de la grandeza del héroe. Este aspecto se describe magistralmente en la siguiente cita, de Martí revolucionario:

Aquellos soñadores / de |realidades venideras, constructores de una nueva sociedad sobre las ruinas de una sociedad decrépita. . renunciaban a la familia y a cuántos bienes se ofrecen. . . Para ellos la felicidad únicamente existe en nosotros, y para sí escogen la senda de pedregal y fango, y esto con una voluntad inquebrantable. . . para Martí la vida fue agonía y deber, y el precio que tuvo que pagar por esa elección del camino del Calvario fue la totalidad de los bienes materiales que se le ofrecía como tentación: el hogar con la familia, la paz bueguesa, la gloria literaria y el respeto de los que a su vez son respetados. ( $\mathrm{p}$. 252)

Masoquismo a gran escala, ciertamente, pero de carácter fundamental tanto para Martí como para su biógrafo: de ahí se desarrollará toda una teoría, coherente y secular, de un exaltado ágape hacia la humanidad, en juego con un ocultado sentimiento erótico, intimo y a la vez mundano. Don Ezequiel, para cimentar su ponencia, cita a Hōlderlin; el tema: la santificación del hombre, del ser humano:

Ese ha de destruir su propia casa y destrozar, como si fuera enemigo, lo que le es más querido; y ha de ver sepultados en sus escombros a su propio padre y a sus propios hijos; si no, nunca será como los dioses, nunca se verá nimbado de su luz.

Creo que aquí reside el eje central del libro, el primum mobile de Martí, según la visión de Martínez Estrada. Finalmente, debido a la voluntad de acero de Martí, la figura del hombre resultará por siempre enigmática, no sólo para los lectores de esta biografía, sino también para su autor mismo. Es por la exaltación abstracta de la humanidad-_ "afectuosidad generosa y dadivosa, de entrega de sí como obsequio y prueba de mutuo ligamen, como hubo de ser el amor entre los cristianos primitivos,', (p. 46), que advierte EME en Marti el corolario inevitable de ese impulso abstracto- ' "el amor sexual fue débil en Martí, comparado con el Eros cosmogónico o ecuménico del que su culto a la familia y la amistad eran reflejos.' (p. 46) Explicar lo anterior le resulta difícil a Martínez Estrada. A pesar de que fue-por inclinación y entrenamiento-una suerte de seguidor de las ideas de Hipólito Taine en lo tocante a la crítica literaria y al género biografía con sus imperativos de raza, ambiente y momento histórico-EME no puede indicar cómo estos elementos entran en la formación del carácter de Martí en su infancia o en su adolescencia-se queda el biógrafo confundido por la característica ex-nibilo de los impulsos del prócer:

La. formación de esta extraordinaria personalidad, aparte las cualidades innatas del genio, que lo fue por igual en los tres dominios de la inteligencia, del sen- 
timiento y de la voluntad, es de por sí un enigma, pues ni los antecedentes de familia ni los de educación y de experiencia,. . . concurren a modelarla y robustecerla, ni halló coyunturas propicias para su desarrollo primario y su natural madurez. Todo lo que fue lo debe a su extraordinaria fuerza de voluntad, a sus sobrenaturales dotes humanas nativas, a su heroico y estoico designio de ser lo que sentía que era, y de hacer lo que, en razón de eso que auténticamente era, tenía el deber de hacer. (p. 9)

La metáfora más adecuada para representar esa obligación final es la de un dios-hechohombre crucificado; curiosamente, fué la madre de Martí, quien humilde y emocionadamente recrimina en vano a su obsesionado hijo. Al recriminarlo nos está indicando cabalmente el ideal de la vida de Martí. En carta de 19 de agosto de 1881, le dice:

Te acordarás de lo que desde niño te estoy diciendo, que todo el que se mete a redentor sale crucificado, y que los peores enemigos son los de su misma raza, y te lo vuelvo a decir; mientras tú no puedas alejarte de todo lo que sea política y periodismo, no tendrás un día de tranquilidad.(p. 35)

EME nos presenta un Martí cuya vida es un símbolo del apátrida, un Martí que renuncia voluntariamente a todo aquello que amaba intimamente, un Martí que se niega aún las ínfimas necesidades de la vida; un Martí, en conjunto, enclavado revolucionario, vidente político, profeta en el erial del periodismo, exilado en un mundo de salteadores de camino y "robber barons," redentor que no pudo redimirse sin quedar aniquilado en el proceso. Aunque la idolatría de Martínez Estrada no deja lugar a la crítica, a través de toda la obra hay, a pesar de su partidarismo, momentos en que el biógrafo se detiene a reflexionar sobre este lado oscuro de Martí y, a veces, preguntas retóricas le detienen momentáneamente en el panegirico de las caracterizaciones que hace del héroe. En un momento dado, EME inquiere un poco plañideramente:

¿Cuando encontramos en Martí efusiones de gozo? ¿Cuándo la alegría de sentirse libre, ligero, luminoso, sino cuando está en marcha al suplicio? Toda su obra trasciende una pena secreta que en las crisis agudas se exhala en ayes de soledad y cansancio, una íntima y recóndita angustia que anubla su mirada, presentándole el mundo como un lugar de penitencia, trabajo, ingratitud, incomprensión y enfermedades. (p. 257)

Tratando de iluminar un poco la cita anterior, me parece que Martínez Estrada está sugiriendo-si bien no explícitamente, claro-algún trauma de la niñez, algún daño psíquico que, aunque cauterizado luego durante su adolescencia y madurez, dejó en el Martí hombre algo muerto, quizás todo un campo de comunicación erótica, total y definitivamente excluído de su vida. En realidad, Martí casi dijo esto en una carta de 1894, y bien pudiéramos considerar sus palabras como su declaración al respecto:

El hombre intimo está muerto y fuera de toda resurrección, lo que sería el hogar franco y para mí imposible, adonde está la unica dicha humana, o la raíz de todas las dichas. Pero, el hombre vigilante y compasivo está aún vivo en $\mathrm{mí}$, como un esqueleto que se hubiese salido de la sepultura. (p. 260)

Así, en la búsqueda del verdadero Martí, EME llega a la conclusión de que ese Martí es 
casi inaccesible, perdido para todos, menos para los sujetos individuales; las cartas de Martí están llenas de sugerencias y ecos solamente, fueron escritas en un código que edifica una pared defensiva alrededor de su alma. Sin embargo, en su búsqueda, EME logra cuajar una manera única de reevaluación y esto lo consigue a través del Diario de campaña de Martí. Esta obra, donde residen las fuerzas telúricas revivificadas en Martí con su regreso a Cuba, le parece a EME "la imagen...más fiel que ninguna otra...el resto es biografía, historia, cultural y moral, política y arte: esto (el Diamio de campaña) es Martí" (p. 381).

Este Mart' verdadero, "real," puede redescubrirse, pero tan sólo a través de las fuerzas telúricas que devela EME desde el alma del prócer. Anteo moderno, Martí se realiza en Martí tan sólo en las páginas últimas de su Diario de campaña y en su otro diario guatemalteco, anterior a éste. Y surge aquí un nuevo aspecto de la relaciórı ęspiritual entre Martínez Estrada y Marti; o sea, el de la tendencia telúrica-heroica-pastoril, ${ }^{34}$ que destila a través de las páginas de la biografía de Martí, principalmente en las secciones tituladas "Sentido Telúrico de la Tierra," y "La Madre Tierra y el Hijo Pródigo." En el mundocreación de Dios, todos los seres son maravillosos y admirables;

No hay aquí jerarquías,ordenaciones artificiales, hechas conforme a las pautas de la clasificación y valoración por su utilidad, o prestancia, o belleza; es la naturaleza sin privilegios ni preferencias, la madre universal ecuánime. . . el amor a Cuba, a su naturaleza virginal y a sus gentes incontaminadas, es la contraparte al rechazo de la civilización fabril y mercantil norteamericana. (p. 401-2)

Este sentir un mundo primario despierta en EME la más extraordinaria concatenación asociativa: Martí, bucólico con ecos de Virgilio y Hesiodo; Martí, dentro del Nirvana budista; Martí, iniciado en los ritos de Deméter y Perséfone; Martí, Colón descubridor de una utopía americana de carácter paradisíaco; Martí, acólito de Tolstoi. Esta última caracterización de Martí la propongo yo porque las descripciones y pinturas del guajiro cubano parecen salidas de un lienzo tolstoiano, copia de la alabanza exagerada del sencillo poder espiritual de los mujics rusos:

Estos guajiros, hombres y mujeres ocupados en las tareas comunes de prepararse el sustento en los trabajos cotidianos de vivir ganándose su pan con las manos que escarban la tierra, y sufriendo cada cual su suerte sin blasfemar y sin quejarse; estos hombres y estos niños hablan una lengua rústica pero que suelen expresar las más altas ideas de la filosofía sapiencial, de la experiencia y del saber de

\footnotetext{
24 Después de todo, ¿qué mayor defensor del poder telúrico que EME en su Radiografía de la pampa? Y alli, en particular, con la sección titulada "Las fuerzas de la tierra"? ¿Y qué otro aspecto del pensamiento de Martínez Estrada causó mayor discusión que éste? Bernardo Canal Feijóo, en una reseña de la Radiografí... protestó ardientemente contra esta veta en EME, refiriéndose a ella como "un bastante pueril geomorfismo espiritual, " un "primario animismo" ejemplo de "mudos terrores informes." Sin embargo, más de 40 años después, Martínez Estrada demuestra que sư telurismo no solo no permaneció inalterado sino que se refinó, dejó de ser pesimista, se generalizó y espiritualizó al contacto con el panteísmó de aquellos escritores con quienes sintió afinidad. Después de todo, EME, como Horacio Quiroga, tenía algo de espíritu franciscano, algo de Rousseau y Thoreau, algo de Tolstoi y D.H. Lawrence. Ese algo de que hablamos es la tendencia heroico-pastoril que también sentían Martí y EME a través de la cual sus deseos de una vida libre dentro de la naturaleza estaban ligados a un sentir revolucionario incipiente y anárquico contra la deshumanización del hombre en la sociedad urbana. De acuerdo con esta concepción, los verdaderos poderes del hombre sólo pueden encontrarse a través de una unión, comunión, con la naturaleza, sobre todo ya que Natura jamás niega nada al hombre, nunca lleva implícita negación alguna; todo en ella es afirmación, exaltación del cuerpo, culminación del yo, vida plenamente vivida.
} 
cosas, tal como brotan en su alma para hablar o para cantar. (pp. 407-408)

El impulso hacia una Arcadia, o el ímpetu utópico en EME y en Martí, nos guiará hacia el problema total de la insistencia, por parte de Don Ezequiel, en la intemporalidad de la figura de Martí, en su compulsión mitificadora y arcaizante del héroe- "sobreviviente" - nos lo asegura el biógrafo- "de una Edad de Oro en la Edad del Hierro, como un caballero de la corte de Arturo en el bric-à-brac de los Estados Unidos: Odiseo u Orestes que reencarna después de treinta siglos, ... discípulo de Platón y Jenofonte, de la galería de Tucídides, Plutarco y Carlyle'' (p. 464). Este extraordinario panteón se edifica sólo para elevar a Martí y situarlo fuera del campo de sus escritos; separarlo, alejar su figura heroica de aquellas presiones naturales a cualquier biografía minuciosa y anexarlo a los llamados "'hombres representativos," ' que tanto Emerson como Carlyle señalaron durante el siglo XIX como paradigmas de humanidad heroica y autosacrificada. Queda así Martí convertido en un principio abstracto, un ente dominado por su visión de poseso. Como conclusión tinal, EME afirma que "efectivamente la clave para interpretar la grandeza humana de Martí es el mito,' y, ciertamente, no hay otra manera de acercarse a la lectura de este esfuerzo gigantesco de simbiosis espiritual y unión psíquica si no es desde el punto de vista del mito, viendo cómo los hechos concretos son elevados consistente y sistemáticamente al campo de la alegoría y la ejemplaridad abstracta.

Ese sentido de la unidad de visión entre Martí y Martínez Estrada es sintomático de la técnica utilizada por Martí en sus medallones biográficos, y EME nos presenta a Martí poseedor de los instintos de un Balzac, discípulo de Klages y Spranger, así como de la pseudociencia-- tan bien mirada en el siglo XIX-de los tipos psico-caracteriológicos. Si bien Martínez Estrada no aboga por la frenología, numerosas páginas están dedicadas a un escrutinio grafológico de los manuscritos martianos. Esto conduce claramente a una cierta clase de tipología del carácter que practicó Martí y de la que se apropia EME como depositario que fuera de un romanticismo bien tardío. Alguien preguntó una vez a Martí cómo había podido penetrar en la psiquis del General-y luego Presidente de los EE. UU.-Ulysses S. Grant:

- "¿Donde conoció usted al hombre, que parece que lo ha retratado usted por dentro?"'

Martí responde:

— "Lo conocí en los hombres! Los espíritus humanos se dividen en familias, como los animales.' (pp. 491-492)

Ásí, podemos explicar las afinidades tipológicas en los bosquejos biográficos de Martí como la relación espiritual entre el autor y el personaje que le ocupa. Vale la pena recordar las descripciones hechas por Marti del heroico norteamericano Wendell Phillips-reformador, abolicionista, defensor de los derechos de los indios y de las sufragistas- hechas por Martí. Allí ocurren las visiones extraordinarias, penetrantes e incisivas que encontraremos también en los bosquejos martianos sobre San Martín, Bolívar, Lincoln y Emerson.

El heroismo martiano, según Martínez Estrada, es igual o superior al de héroes similares de la antigüedad, sobre todo porque Martí se formó a sí mismo con las cualidades 
que encontró en sí mismo, sin la ayuda de un medio ambiente y circunstancias propicias a su desarrollo. Es curioso que, a pesar de ser esta obra un panegírico de la vida de Mart́, encontramos en ella juicios críticos severos-desde el punto de vista literario-sobre la obra escrita del prócer. Por ejemplo, en un párrafo casi al final de la biografía, EME intenta desviar el valor de los artículos periodísticos de Martí para que éstos, con su poco valor, no resten importancia al verdadero mérito del hombre:

... es indiscutible que durante todas sus obras pesan sobre ellas, porque pesan sobre él, los malos ejemplos de un teatro de zarzuela, de una crítica de gacetilla, de una poesía de profesores de poética y de una filosofía de seminaristas. . . las máculas que hallamos en su estilo de prosista y de orador, en sus versos en que la facilidad del genio suena muchas veces a descuido y frivolidad, se deben a los malos ejemplos de su juventud. . . ninguna influencia perniciosa de esta clase observamos en la formación y el desarrollo pleno de su personalidad, y sólo perjudica a la exterioridad estilistica, a la forma de una parte de su obra (p. 512).

Aunque a primera vista puede parecer que el juicio anterior es demasiado severo para con el Martí esteta, creo que es una opinión bien sintética de la revisión total de las ideas de Martínez Estrada en lo tocante a la relación entre literatura y sociedad efectuada en él durante su estancia en Cuba. No olvidemos que la visión de EME hacia Martí subraya el hecho de que

...la inteligencia no es un capital privado que pueda usarse en propio beneficio y caprichosamente, sino que su aplicación y usufructo pertenece, como todo bien social, a la comunidad (p. 528).

Estas palabras, que sitúan las obras de la imaginación al servicio de la sociedad--sobre todo de la sociedad revolucionaria--reflejan la atenta y cuidadosa lectura por parte de EME del discurso de Fidel Castro "Palabras a los intelectuales," (junio de 1961). Ejemplo y prueba de la intensidad de su lectura y de cómo ésta le afectó, la tenemos en un importante ensayo titulado "Por una alta cultura popular y socialista cubana." En el mismo, luego de citar pasajes extensos de Fidel Castro sobre la responsabilidad social del artista para con el pueblo y con el proceso revolucionario, Martinez Estrada injerta un comentario que asocia en línea directa las teorias literarias de Castro con el ejemplo práctico de José Martí medio siglo antes. La médula del ensayo está en las siguientes palabras:

Imagino la extraneza que habrá producido en los escritores y artistas hispanoamericanos que hayan tenido la rara oportunidad de leer las "Palabras a los intelectuales," sobre todo si no conocen a Martí sino por las antologías. Tanto en su obra escrita...cuanto en la consagración de su vida entera, tenemos el paradigma de los deberes del intelectual para con la sociedad, y el reproche implícito de lo que $n o$ hemos hecho...El primer sacrificio de Marti, en el presidio político, en aras del bien del projimo, es el de su inteligencia que afina y fortalece para que sirva como una espada bien templada a la libertad de Cuba y no su bienestar y su fama. Una 
fuerza sobrenatural lo sostuvo, iluminó su pensamiento, purificó su alma y armó su brazo: su amor al pueblo. ${ }^{25}$

Esta visión de un santo secular de la literatura y de la revolución conlleva en la presentación de Martí ecos de Moisés, Ismael y Jeremías. No hay otra forma de entender el impulso hacia la redención espiritual en Martí y en EME si no es examinando a ambos como modelos catequizantes de un culto laico hacia y por la humanidad, culto que se refiere no a las parodias grotescas de la ley civil sino a una ley superior dentro de cada individuo que, como en el Oversoul de Emerson, alumbra el camino del hombre y le sirve de guía incorruptible. " $E 1$ derecho que Martí respeta y aplica es el derecho de origen religioso que se transfiere al pueblo y que no reconoce ninguna instancia superior al dictamen de la conciencia." Conciencia que guió a Benito Juárez--bienamado de Martí--, la conciencia, si se quiere, de Thoreau en su tratado sobre la Desobediencia civil. Es hacia esta mentalidad de conciencia social, insiste EME, que la imaginación literaria del autor debe dirigirse; la responsabilidad social del escritor debe dominar, a fin de cuentas, todo tipo de estética inútil, todas las fantasías nacidas en cualquier torre de marfil. Afirma Castro en sus "Palabras a los intelectuales," y asiente EME citarlas:

El revolucionario pone algo por encima de todas las demás cuestiones: el revolucionario pone algo aún por encima de su espíritu creador: pone la Revolución por encima de todo lo demás, y el artista más revolucionario sería aquel que estuviera dispuesto a sacrificar hasta su propia vocación artística por la Revolución... ${ }^{26}$

¿Se sacrifica--se crucifica?--al escritor y a la escritura? Bien puede ser, pero es un sacrificio llevado a cabo voluntariamente por la causa revolucionaria, y debemos suponer que los entes prometeicos, a pesar del sufrimiento, encuentran en su martirio una ilusión y una esperanza interior.

Para finalizar, deseo notar que Emanuel Carballo formuló la siguiente pregunta a EME al pasar éste por México, de regreso a Bahía Blanca y a su muerte;

E.C.-- “ ¿Es el mismo Don Ezequiel que se fue de México a Cuba en 1960 y el que regresa rumbo a la Argentina en 1962?

E.M.E.--Yo puedo decirle que en $\mathrm{ml}$ mismo se ha operado, en cierto grado, en cierta escala, un fenómeno religioso de transmutación...Y Yo he recibido en Cuba la consagración de mi devoción. Hasta entonces yo era un practicante secular o laico de un credo de redención humana. Después de haber estado en Cuba considero que ese credo no es meramente filosófico o intelectual sino que es de carácter humano, moral y religioso...De modo que he vuelto hecho un sacerdote, $\mathrm{mi}$ amigo: ateo incrédulo, antieclesiástico, ácrata, todo lo que usted quiera, pero religioso. Eso es

25 “'Por una alta cultura popular y socialista cubana" en Mi experiencia cubana, pp. 186-187.

26 Op. cit., p. 183. 
lo que yo he aprendido en Cuba.", 27

Martí y Ezequiel Martínez Estrada, dos en uno--el muerto ha convertido al vivo sobre todo a su doctrina de sacrificio y redención por la humanidad. En esta transfiguración, Don Ezequiel es el vehículo--el médium--a través del cual el alma de José Martí nos es dada a todos, para siempre.

New York University

ALEXANDER COLEMAN

Traducido del inglés por

PEDRO BOVI-GUERRA

${ }^{27}$ Revista de la Casa de las Américas, Nov-Dic. 1965, Núm 33, pp. 48-49. 
